\title{
Exploring the Influence of the Scale of Higher Education on My Country's Economic Growth Based on the Multiple Regression Model
}

\author{
Wang Jing ${ }^{1, a^{*}}$,Yan Chenxiao ${ }^{2, b}$, Zhang Tingting ${ }^{3, c}$

\begin{abstract}
${ }^{I}$ School of Finance and Public Administration, Anhui University of Finance and Economics, Longzihu District, Bengbu, Anhui, China

${ }^{2}$ School of Economics, Anhui University of Finance and Economics, Longzihu District, Bengbu, Anhui, China ${ }^{3}$ School of International Economics and Trade, Anhui University of Finance and Economics, Longzihu District, Bengbu, Anhui, China

a*1656376964@qq.com

${ }^{b} 1464712012 @ q q . c o m$

c1514843072@qq.com
\end{abstract}

\begin{abstract}
At present, my country's economic development has entered a new journey of socialist modernization, and correspondingly, higher requirements have been put forward on the level and level of my country's education. However, how does the scale of higher education affect my country's economic growth? This paper starts from the two dimensions of the scale and quantity, structure and quality of higher education, establishes a systematic index system for the scale of higher education, and analyzes the impact of higher education scale construction on my country's economic growth by setting a multiple regression model. The research results show that the scale of higher education is closely related to my country's economic growth. Quality expansion of higher education, optimizing the structure of higher education, increasing funding for higher education, and taking the path of connotative development can promote further economic growth in my country.
\end{abstract}

Keywords: Higher Education Scale, Economic Growth, Multiple Regression Model

\section{基于多元回归模型探析高等教育规模对我国经济增长 的影响}

\author{
王京 $1, \mathrm{a}^{*}$ 问晨晓 $2, \mathrm{~b}$ 张婷婷 $3, \mathrm{c}$
}

${ }^{1}$ 安徽财经大学财政与公共管理学院, 龙子湖区, 蚌埠市, 安徽, 中国

2 安徽财经大学经济学院, 龙子湖区, 蛙埠市, 安徽, 中国

3 安徽财经大学国际经济贸易学院, 龙子湖区, 蚌埠市, 安徽, 中国

a*1656376964@qq.com

${ }^{b} 1464712012 @ q q . c o m$

c1514843072@qq.com

\section{摘要}

目前我国经济发展已迈入社会主义现代化新征程，与之相应的对我国教育的层次与水平提出了更高的要求。然 而高等教育规模对我国经济增长有着怎样的影响？本文从高等教育规模的规模与数量、结构与质量两个维度 出发，建立高等教育规模系统指标体系，通过设定多元回归模型探析高等教育规模建设对我国经济增长的影 
响。研究结果表明, 高等教育规模建设与我国经济增长密切相关, 质量化扩大高等教育规模、优化高等教育结 构、加大高等教育经费投入以及走内涵式发展道路等能够促进我国经济的进一步增长。

关键词: 高等教育规模, 经济增长, 多元回归模型

\section{1. 引言}

习近平主席在党的十九大报告中作出中国特色 社会主义进入新时代的重大政治论断，相应的我国经 济飞速发展, 已迈入社会主义现代化建设新征程, 新 时代人们对知识的需求日益增长, 高等教育在我国经 济增长方面的提振作用日益显现。越来越多的学者将 经济发展同教育水平联系在一起, 教育经济学科存在 的合理性日益凸显。王应密等 (2021) 基于中国省域 面板数据研究了高等职业教育对经济增长的贡献率, 认为教育对经济增长的贡献率与高职教育对经济增 长的贡献率呈正相关, 高职教育经济增长贡献率地区 差异显著。苏鸿儒等 (2021) 从粤、鲁、浙、苏四省 份比较出发, 测度了高等教育与区域经济的耦合协调 度, 认为四省份应从自身经济产业结构特色寻找突破 口, 增强高等教育与区域经济发展的协调性。

然而高等教育与经济增长之间究竟存在怎样的 关联, 高等教育规模指标设置应以何为依据参考? 综 合已有文献, 本研究从全国角度出发, 通过建立多元 回归模型挖掘高等教育与经济增长之间的关系, 探索 高等教育规模合理化指标设置并提出了相应的对策 与建议, 本研究对我国政府调节高等教育投资力度, 合理配置高等教育规模资源具有重要借鉴意义。

\section{2. 研究方法与数据来源}

\section{1 研究方法}

\subsection{1 文献研究法}

通过检索数据库查阅与本文相关的国内外文献 资料、翻阅目前已有的相应书籍、指标体系, 并进一 步整理分析总结，对本文的相关概念进行了界定，明 确了模型设定的理论与经济意义, 并选定了模型设定 的解释变量与被解释变量。

\section{1.2 实证分析法}

选取 2000-2019 年 20 年的相关数据作为样本建 立多元线性回归模型, 利用 EViews 9.0 软件对数据 进行分析处理, 根据数据处理的统计参数结果得出结 论并提出建设性意见。

\section{2 数据来源}

为研究高等教育规模建设对我国经济增长的影 响, 基于常识性认知与文献理论基础, 本文选取了国 内生产总值 GDP 作为被解释变量来综合反映我国经济 增长状况; 在解释变量层面, 本文从规模与数量、结 构与质量两个维度选取了共 5 项指标来反映我国高等 教育规模的建设发展状况。本文的分析数据均来自于 中国统计年鉴、中国教育统计年鉴及中国教育经费统 计年鉴, 数据区间为 2000 年到 2019 年共计 20 年。

表 1 高等教育规模系统指标体系

\begin{tabular}{|c|c|c|c|}
\hline \multirow{3}{*}{$\begin{array}{l}\text { 高等教 } \\
\text { 育规模 } \\
\text { 系统 }\end{array}$} & 要素层 & 二级指标 & 选取说明 \\
\hline & 规模与数量 & $\begin{array}{l}\text { 专任教师人数 } \\
\text { 毕业生人数 } \\
\text { 在校学生情况 }\end{array}$ & $\begin{array}{l}\text { 反映高等教育的师资力量 } \\
\text { 反映高等教育绝对人力资本输出规模 } \\
\text { 反映高等教育的规模 }\end{array}$ \\
\hline & 结构与质量 & $\begin{array}{l}\text { 生均财政性教育经费 } \\
\text { 师生百分比 }\end{array}$ & $\begin{array}{l}\text { 反映高等教育的投资力度 } \\
\text { 反映高等教育资源配置结构 }\end{array}$ \\
\hline
\end{tabular}

在构建的高等教育规模系统指标体系中, 部分指 标的数据可以从统计年鉴中直接获取, 其余指标的数 据则需通过计算获得，具体计算公式如下 ${ }^{[1]}$ :
生均财政性教育经费 $=\frac{\text { 财政性教育经费 }}{\text { 在校学生情况 }}$ 
师生百分比 $=\frac{\text { 专任教师人数 }}{\text { 在校学生情况 }} \times 100 \%$

\section{3. 实证分析}

\section{1 模型设定}

\subsection{1 趋势图分析}

运用 EViews 9.0 软件对高等教育规模指标体系 与我国经济增长状况进行趋势图分析得到结果如图 1:

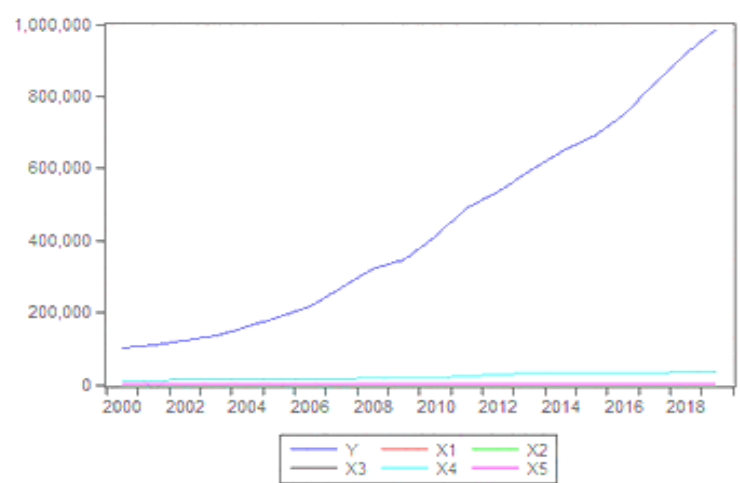

图 1 各变量趋势图

趋势图显示, 我国经济增长状况与高等教育指标体 系的差异明显, 但变化的趋势一致, 且从趋势图中可以 直观的看出随着解释变量的增长变动, 被解释变量与解 释变量之间近似呈现正相关，具有较强的相关性。

\section{1.2 相关系数分析}

在 EViews 9.0 软件中键入 COR Y x1 x2 x3 x4 x5 得到我国经济增长与高等教育规模指标体系的相关系 数表如表 2:

表 2 各变量相关系数表

\begin{tabular}{|c|c|c|c|c|c|c|}
\hline & $\mathrm{Y}$ & $X_{1}$ & X2 & X3 & $X_{4}$ & $\times 5$ \\
\hline$Y$ & 1.000000 & 0.920659 & 0.922870 & 0.921840 & 0.988191 & -0.651658 \\
\hline$X_{1}$ & 0.920659 & 1.000000 & 0.996048 & 0.999356 & 0.898820 & -0.844825 \\
\hline X2 & 0.922870 & 0.996048 & 1.000000 & 0.993715 & 0.903920 & -0.809976 \\
\hline$X_{3}$ & 0.921840 & 0.999356 & 0.993715 & 1.000000 & 0.897376 & -0.854250 \\
\hline$X_{4}$ & 0.988191 & 0.898820 & 0.903920 & 0.897376 & 1.000000 & -0.607277 \\
\hline$\times 5$ & -0.651658 & -0.844825 & .0 .809976 & -0.854250 & -0.607277 & 1.000000 \\
\hline
\end{tabular}

相关系数表显示, 各解释变量之间都表现出强相 关性, 初步表明我国经济的增长与高等教育的规模建 设密切相关, 其中 GDP 与生均财政性教育经费 $\mathrm{x} 4$ 的 相关系数为 0.988191 , 表明 $\mathrm{Y}$ 与 $\mathrm{x} 4$ 之间可能存在高 度线性相关关系; $\mathrm{x} 1 、 \mathrm{x} 2 、 \mathrm{x} 3$ 与 GDP 的相关系数均大 于 0.92 , 表明可能存在线性相关关系; $x 5$ 与 Y 之间 的相关系数小于 0.7 , 相关性较弱。

基于趋势图与相关系数分析, 本研究将设定多元 线性回归模型来拟合高等教育规模建设对我国经济 增长的影响, 公式如 (3):

$$
Y_{i}=\beta_{1}+\beta_{2} x_{1}+\beta_{3} x_{2}+\beta_{4} x_{3}+\beta_{5} x_{4}+\beta_{6} x_{5}+u_{i}
$$

\section{2 多元线性回归模型的估计}

将数据导入 EViews 9.0 软件, 估计多元线性回 归模型参数, 结果如图 2:

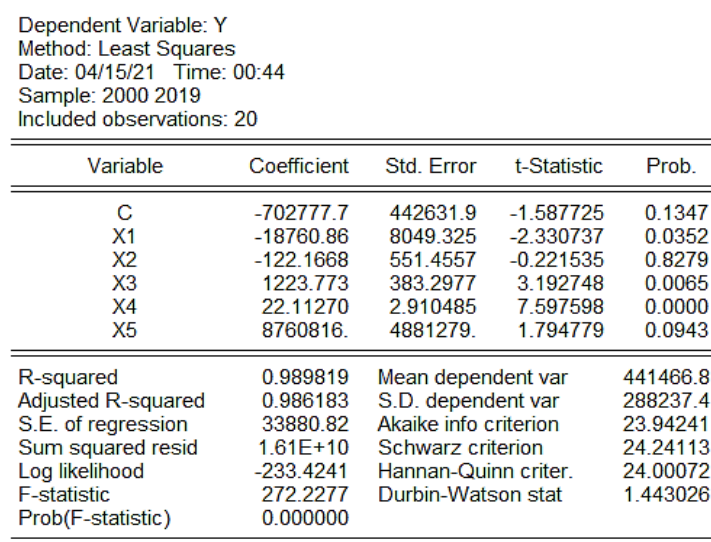

图 2 多元回归模型参数估计结果

模型估计结果显示, $R^{2}=0.989819, \bar{R}^{2}$ $=0.986183$ 接近于 1 , 初步表明模型对样本的拟合程 度较好。而针对 $H_{0}: \beta_{2}=\beta_{3}=\beta_{4}=\beta_{5}=\beta_{6}=0$, 给定 $\alpha=0.05$, 可知 $F=272.2277>F_{\alpha}(5,20)$, 应拒绝原假设 $H_{0}$, 说明 回归方程显著, 即高等教育规模指标体系变量联合起 来, 确实对我国经济增长有着显著影响。从经济意义 层面来看, 专任教师人数与毕业生人数两个变量的参 数为负值, 不符合实际经验判断, 经济意义不合理, 解释变量之间可能存在相关关系, 即模型可能存在严 重的多重共线性。

为修正模型的多重共线性, 采用逐步回归法优化 模型, 最终建立多元线性回归模型:

$$
Y_{i}=-127687.4+138.45 x_{2}+27.03 x_{4}-1701246 x_{5}
$$

模型估计结果表明，在假定其他高等教育指标不 变的情况下, 毕业生人数每增加一万人, 我国 GDP 将 平均增长 138.45 亿元; 生均财政性教育经费支出每 增加 1 元/人, 我国 GDP 将平均增长 27.03 亿元; 综 合图 1 与图 2 模型与数据分析可知, 在校生人数与专 任教师人数与我国 GDP 呈正相关, 对我国经济发展水 平影响较高, 二者的最佳配比即师生百分比在特定的 $P$ 值范围内与我国经济增长呈正相关, 达到峰值后, 与经济增长呈负相关, 相较于其他指标对我国经济增 长的影响程度最大。

\section{4. 结论与建议}

新经济增长理论认为, 经济增长的来源不仅是资 本和劳动力等因素质量的增加, 而是这些因素质量的 提高。高等教育作为提高人力资本的重要途径, 源源 不断地为社会输送人才 ${ }^{[2]}$, 其规模的有效建设对经济 增长有着重要影响。多元回归模型研究表明, 通过增 加专任教师人数、在校生人数, 提高毕业生源输出量 等措施扩大高等教育教学规模, 能够促进我国经济发 
展水平的提高; 而通过增加财政性教育经费支出, 优 化高等教育师生百分比等调节高等教育教学结构也 有利于我国经济的进一步增长, 即高等教育规模建设 与我国经济增长密切相关。

高等教育是一个国家乃至全球经济增长、繁荣的 关键驱动力之一 ${ }^{[3]}$, 故基于此次研究数据与结论, 对 我国高等教育规模建设提出以下建议:

(1) 扩大高等教育教学规模, 提升高等教育教学 质量

教学规模是绝对人力资本输出的重要保障因素 之一, 扩大高等教育教学规模为我国经济增长提供原 动力。故我国应持续加强高等教育学校建设, 扩充高 校专任教师队伍, 加大招生力度。当然, 高等教育在 规模扩张的同时更应注重质量的提升, 坚持 “人才强 校” 战略, 以我国经济发展需求为导向, 建立一支与 教育资源、人才规模相适应的高素质专任教师队伍, 提高高校综合实力与竞争力, 走内涵式发展道路 ${ }^{[4]}$ 。

（2）优化高等教育结构, 坚持产学研深度融合

高等教育结构是高等教育规模建设的骨架支撑, 维持高等教育系统内部各因素的稳定性和比例关系 是建设与经济发展相适应的高等教育规模的必要环 节。故我国高等教育建设应优化师资与学生数量配比, 加大财政性教育经费支出, 创新 “校企、校研、校校” 等合作机制, 紧密结合市场需求, 建立校企高新技术 供需对接机制。通过深层次教育改革枆动新常态教学 改革, 以此提高高校的教学水平, 进一步加快高校教 育结构的调整和转型 ${ }^{[5]}$ 。

\section{REFERENCES}

[1] coordinated development of higher education and regional economy_ Based on the comparison of Guangdong, Shandong, Zhejiang and Jiangsu [J]. China Economic and Trade Guide , (04) :141144.

[2] Cai X.(2021) Research on the Contribution of Regional Higher Education to Local Economic Growth [D]. Southwest University.

[3] Yang Y, Su K.(2021) Research on the relationship between higher education and regional economic growth-Taking Fujian Province as an example $[\mathrm{J}]$. Time-honored brand marketing, (03):69-70.

[4] Dai X.(2020) Research on the impact of Hunan's higher education scale on regional economic growth based on VAR model[J]. Journal of Changsha Civil Administration Vocational and Technical College,27(04): 74-77.

[5] Zhao H.(2018) Research on the adjustment and transformation of university teaching management structure in the new era[J]. Curriculum Education Research,(18): 20. 